\title{
La musicalización diegética de la crisis en el cine negro hollywoodiense de los años 40 . La música clásica como signo del conflicto
}

\author{
Judith Helvia García Martín ${ }^{1}$
}

Recibido: 22 de diciembre de 2017 / Aceptado: 5 de marzo de 2018

Resumen. El estado de crisis es inherente al cine negro. Este es representado en un género que se alimentó del bagaje cultural aportado por directores cuya procedencia centroeuropea y ascendencia judía condicionaron los recursos narrativos y estéticos que se utilizarían para plasmar el drama y angustia propios del film noir. Uno de los elementos de representación de estas crisis fue la música, tanto incidental como diegética. Por el carácter eminentemente realista de este cine, prestaremos atención a la segunda, concretamente, a la denominada música clásica. Tras el visionado de cincuenta películas de la edad de oro del cine negro hollywoodiense, observamos que esta música se emplea como elemento de representación de crisis culturales, sociales y personales, y su uso funcional juega un papel decisivo en la pervivencia del canon musical interpretativo, así como de los valores asociados a su significado. Palabras clave: Cine negro; Hollywood; década 1940; música diegética; música clásica; crisis

\section{[en] Source Musicalization of Crisis in the 40s Hollywoodian Film Noir Genre. Classical Music as a Sign of Conflict}

\begin{abstract}
The state of crisis is inherent in film noir. It is represented in a genre that was nourished by the cultural baggage of several directors whose Central European origin and Jewish ancestry conditioned the narrative and aesthetic resources that would be used to capture the drama and anguish of film noir. One of the key elements of representation of these crises was music, both incidental and diegetic. Due to the eminently realistic nature of this cinema, we will focus on the second and, specifically, the so called classical music. After viewing fifty films from the Golden Age of film noir in Hollywood, we observed that this music is used as an element of representation of cultural, social and personal crises, and its functional use plays a crucial role in the survival of the interpretative musical canon, as well as the values associated with its meaning.
\end{abstract}

Keywords: film noir; Hollywood; 40s; source music; classical music; crisis

Sumario. 1. ¿Crisis? ¿Qué crisis? 2. De entre todas las músicas, ¿por qué la clásica (de nuevo)? 3. Crisis cultural: Estados Unidos mata al padre. 4. Crisis social: música clásica ¿para todos? 5. Crisis personal: las sombras son más oscuras al lado de una luz radiante. 6. Últimas reflexiones: el canon musical como signo del conflicto. 7. Anexo. 8. Bibliografía

Cómo citar: García Martín, J. H. (2018). La musicalización diegética de la crisis en el cine negro hollywoodiense. La música clásica como signo de conflicto, en Área Abierta. Revista de comunicación audiovisual y publicitaria 18 (3), 389-404. http://dx.doi.org/10.5209/ARAB.58492

1 Universidad de Salamanca (USAL)

E-mail: helvia@usal.es 


\section{1. ¿Crisis? ¿Qué crisis?}

Hablar del film noir y crisis resulta casi un pleonasmo, pues ambos conceptos están irremediablemente entrelazados. Pocos géneros cinematográficos se han preocupado tanto por reflejar todo tipo de crisis: económica, social, moral... Interpela a la sensibilidad del espectador, ofreciéndole un relato incómodo de los males que aquejan a la sociedad y las injusticias derivadas de éstos, partiendo de tramas que giran en torno al crimen (Santamarina, 1999: 12-13). Para ello recurre a narraciones que oscilan entre el expresionismo onírico y el documentalismo, hasta donde la censura de la época lo permitía ${ }^{2}$ (Coma, 1990: 46-47), con personajes moralmente ambiguos. En palabras de Simsolo (2007: 17-19), "este cine amalgama las complejidades del alma humana... En el cine negro, las sombras y luces persiguen a unos seres que se debaten en un no man's land".

Todo esto provoca irremediablemente también una crisis en el propio espectador que, acostumbrado a mensajes unívocos, de repente "tiene la sensación de que todos los componentes del estilo noir buscan el mismo resultado: desorientar a los espectadores, que pierden sus marcos de referencia habituales" (Borde y Chaumeton, 2002: 12) ${ }^{3}$. Aunque los recursos narrativos y estéticos para la transmisión de este mensaje venían forjándose desde antes, su codificación en el cine cristaliza en los productos hollywoodienses de los años cuarenta, y no por casualidad. Borde y Chaumetonn (2002: 29) defienden que esta década supone un punto de inflexión en el cine estadounidense fruto de la implicación del país en la Segunda Guerra Mundial, momento a partir del que se observa que Hollywood trata de evolucionar a una forma de arte más auténtica, incluso brutal.

Como señalábamos antes, la temática incluye un crimen que transgrede el orden establecido. ¿Qué diferencia entones el género negro del policíaco? Aquél dará un paso más allá, dando importancia al contexto y asumiendo un enfoque relativista que nos permite justificar los actos, a veces delictivos, del protagonista con el que el espectador debe identificarse (ya sea el detective anti- héroe, el inspector de policía, la mujer fatal o el propio criminal, arquetipos del género señalados por Martín, 2007: 26-30).

Los elementos estéticos son herederos directos del cine alemán anterior al nazismo y del realismo francés, importado a los Estados Unidos por los exiliados de la Segunda Guerra Mundial que se refugiaron en Hollywood. Con ellos trajeron las crisis personales ocasionadas por el conflicto bélico, representando una realidad deformada artísticamente para producir un sentimiento de angustia ligado a la desconfianza respecto al orden establecido (Simsolo, 2007: 19-20). Por ello, en el aspecto visual, los recursos expresionistas son los más empleados para transmitir este carácter angustioso: luz contrastada, caras fuertemente iluminadas, encuadres claustrofóbicos... (Place y Peterson, 1996: 66).

2 En 1930 William Hays, presidente de la Motion Picture Production and Distribution of America, implantó el Código Hays, una serie de reformas vigentes hasta 1966 que establecían evitar la sordidez y los temas escabrosos (Rodríguez de Austria, 2015: 186).

3 Las citas tomadas de bibliografía en inglés se ofrecerán traducidas por la autora. No obstante, los diálogos extraídos de las películas se conservarán en su idioma original, por los matices relevantes que pueden aportar en relación al tema tratado aquí. 
Pero el recurso estético que más nos interesa en este artículo es el sonoro. Aquí queremos preguntarnos de qué manera el cine negro recurre al ingrediente musical como vía de representación de estas crisis. Para ello hemos realizado una selección de 18 películas $^{4}$ del género negro realizadas en Estados Unidos durante la década de los cuarenta ${ }^{5}$, incompleta sin duda, pero obligada dados los requisitos de extensión para este artículo. Y puesto que lo que se busca es la representación sonora de la crisis de forma realista y contemporánea a los acontecimientos narrados, hemos elegido centrarnos en la música diegética, más elocuente a la hora de establecer códigos culturales de representación del conflicto — sobre todo externo al personaje - que la música extradiegética.

También sería interesante, aunque inabarcable en este estudio, abordar las estrategias de representación musical de la crisis en este cine a través de la música extradiegética, que con toda seguridad utilizan recursos que entroncan con el lenguaje musical escénico y sinfónico de la Europa tardo decimonónica. Al respecto conviene tener en cuenta aquí las palabras de Brown (1994: 96):

No sorprende que, dados los orígenes vieneses de compositores de cine del primer Hollywood como Max Steiner y Erich Wolfgag Korngold, y el origen centroeuropeo de muchos otros como Franz Waxman, mucha de la música que acompañó a las primeras películas sonoras tuviera un indudable perfil tardorromántico ${ }^{6}$.

4 Sin entrar a debatir qué es cine negro (pues no es el objeto de este artículo), hemos optado por extraer esta selección de las películas más mencionadas en enciclopedias, manuales y monografías de cine negro — consultar bibliografía - La muestra original estaba constituida por 50 películas, de las cuales se han destilado las 18 que analizaremos aquí por ser aquellas que contienen música clásica diegética. He aquí los otros 32 títulos: The Letter, The Maltese Falcon, High Sierra, The Glass Key, Johnny Eager, Margin for Error, Shadow of a Doubt, Phantom Lady, Laura, The Woman in the Window, Double Indemnity, Murder, My Sweet, The Postman Always Rings Twice, The Big Sleep, Gilda, Criminal Court, The Lady from Shanghai, Lady in the Lake, Dark Passage, Out of the Past, Key Largo, The Dark Past, The Naked City, Force of Evil, Sleep, my love, Shockproof, The Big Clock, White Heat, Criss Cross, Caugth, Deadly is the Female, Dark City.

5 Este período nos resulta de interés por varios motivos: por una parte, constituye la época de consolidación de los rasgos del género negro; además, es un período marcado por un cambio en la identidad de Estados Unidos de cara al exterior, lo que conlleva la resignificación de algunos símbolos identitarios; por último, es una década durante la que las producciones de Hollywood estuvieron muy frecuentadas por directores y compositores europeos (o de ascendencia europea) lo cual, como señalaremos en las conclusiones, creemos que condicionó la elección del repertorio diegético.

6 Brown (1994: 43) defiende también que los códigos de esta música funcionan mucho mejor en la música extradiegética para facilitar su manipulación a lo largo de la película — cambios entre modos, en las estructuras rítmicas y armónicas, la fraccionalización de un tema en varios motivos...-. Y efectivamente, los compositores de las bandas sonoras de estas películas se formaron en la herencia del sinfonismo postromántico. En este sentido resulta interesante la declaración de Christopher Palmer acerca de la formación de Roy Webb quien, según el compositor, durante su formación en la Universidad de Columbia "fue alimentado con una dieta a base de Bach y Beethoven: su profesor utilizaba las fugas de Bach como base para su educación, y más tarde Webb reconocería estar agradecido por el rigor de esta formación" (https:/www.naxos.com/person/Roy_Webb/22777. htm, consultado el 10 de diciembre de 2017). 


\section{De entre todas las músicas, ¿por qué la clásica (de nuevo)?}

Aunque palabras como jazz, swing y blues crecen junto al cine negro - así podemos leerlo en estudios monográficos como los de Butler, 2002; o Wagner, 2017-, dejaremos el abordaje del papel de las músicas populares urbanas en este género para futuras investigaciones, y en esta ocasión nos centraremos en esa controvertida etiqueta que constituye la música clásica, a la que Brown se refiere como "música intelectual, que se opone a formas más populares, ya sean canciones, bailes, jazz o lo que sea" (Brown, 1994: 39).

Con todas las salvedades que se puedan hacer a esta definición, para evitar perdernos en disquisiciones que nos extraviarían de nuestro propósito inicial, dejamos establecido que para este contexto consideraremos clásica toda pieza de carácter no popular, diferenciado de esas "canciones, bailes, jazz, o lo que sea", y que se refiere al repertorio desarrollado en Europa entre los siglos XVIII y principios del XX. Así, encontramos que en el film noir se ha incluido la obra de compositores como Beethoven, Strauss o Wagner, entre otros. Un repertorio que en el Nuevo Mundo empezaba a adquirir ya en estos años significados asociados con la élite social, económica o intelectual—, desligado de la música popular accesible — tanto para el consumo como para su interpretación - a cualquier ciudadano de a pie, una codificación que perdura hasta hoy.

A través de todos los significados adquiridos asociados al repertorio clásico, y que hemos podido destilar del visionado de estas dieciocho películas, hemos observado que, de entre todos los tipos de crisis implícitas en el cine negro, la música clásica suele representar tres de ellas, a saber: cultural, social y personal.

\section{Crisis cultural: Estados Unidos mata al padre}

Los años cuarenta suponen en Estados Unidos un punto de inflexión en sus relaciones de política exterior. Si hasta finales del siglo XIX habían permanecido al margen de los asuntos tanto europeos como del resto del mundo, su crecimiento durante el siglo XX impulsó al país a participar de forma activa en la diplomacia mundial. Eso incluyó la Segunda Guerra Mundial, momento a partir del cual la expansión de su poder militar e influencia cultural ya sería imparable hasta nuestros días (Degler, 1986: 267).

En este contexto, la herencia europea lucha por sobrevivir frente la pujante identidad norteamericana: todo lo que represente a aquella, incluyendo la música clásica, se asocia a lo viejo, lo caduco y, como veremos más adelante, lo elitista. Mientras tanto, la música estadounidense, principalmente de carácter popular como el jazz, ya no se circunscribía al nightclub. Tras varias décadas habiéndose escuchado en entornos nocturnos, poco recomendables e incluso clandestinos, por fin se hacía con las grandes salas de conciertos ${ }^{7}$, y se veía como signo de la reafirmación de

7 Como ejemplo, la web del Carneggie Hall relata su historia, diferenciando entre "Classical artists" y "Jazz, Folk and Pop", haciéndose fuertes estos últimos en este auditorio sobre todo a finales de los años 30: "El concierto de Benny Goodman y su banda en 1938, uno de los eventos más celebrados en la historia del Carnegie Hall, constituyó una de las primeras veces en que la gente se sentó a escuchar jazz, y una de las primeras 
la identidad norteamericana y sus valores (progreso y modernidad), frente a esa música de la vieja y cansada Europa. Esta disociación entre el repertorio clásico y la población estadounidense puede leerse en el siguiente diálogo de ¿Ángel o diablo? (Fallen Angel, Otto Preminger, 1945) en el que Eric, un cazafortunas, se refiere a estos compositores como "old boys", mostrando además un nulo conocimiento o apreciación de su música al decir que toda suena igual:

Eric: Very good performance, Miss Mills. Please, go on. Beethoven never sounded so good before. June: I wasn't playing Beethoven.

Eric: No? Why sure, it was Brahms! The old boys do sound alike, don't they? I mean in spots...

June: What "spots"?

Eric: You know: the way they begin, the way they end, sometimes in the middle, like the piece you were just playing, Brahms, uh...

June: It wasn't anything. I was just improvising.

Eric: Well if Brahms didn't write that, you went him one better! That was beautiful. It was classical. It was inspiring. You know, you belong in Carnegie Hall.

Esta crisis de identidades encuentra representaciones diversas en el cine negro de los cuarenta, y tal vezuna de las más ilustrativas sea El crepúsculo de los dioses (Sunset Boulevard, Billy Wilder, 1950). Norma Desmond, una actriz jubilada que vivió sus días de gloria en la época del cine mudo y abandonó su trabajo tras la llegada del sonoro, vive retirada y acoge en su casa al guionista Joe Gillis. Todo lo que la rodea nos recuerda a una prima donna venida a menos, y destila decrepitud y un esplendor perdido. Uno de los objetos extravagantes y caprichosos que se pueden encontrar en su salón es un órgano de tubos — ¿reales o canónigos ${ }^{8}$ ? — que permanece mudo excepto cuando su mayordomo y ex marido Max interpreta la Toccata en Re menor. Tanto la elección del instrumento ${ }^{9}$ como la de la pieza siguen la línea de tantos otros elementos estéticos que en la película representan la decadencia de la actriz y del mundo ilusorio del que se rodea. El instrumento es tan inservible como el resto de cachivaches y recuerdos que alberga el salón, y el repertorio que su mayordomo toca en él, tan caduco como la propia carrera de la actriz, en contraposición al repertorio popular que Gillis presencia cuando acude a una fiesta de Nochevieja. El repertorio europeo es el pasado, anacrónico; el popular estadounidense es el futuro y goza de tan buena salud como el año nuevo que se celebra en esa celebración.

actuaciones en las que intérpretes blancos y afroamericanos aparecieron juntos en un escenario" ("Carneggie Hall, then and now". https://www.carnegiehall.org/-/media/CarnegieHall/Files/PDFs/About/History/Thenand-Now_2017-2018.pdf?la=en\&hash=B177B570CB32E6511130FC608081E33054B477AC )

8 Tubos ornamentales, que no están conectados al secreto del órgano y por lo tanto no suenan.

9 La presencia de la Toccata en Re menor tocada en un órgano en el cine como elemento de representación de personajes y ambientes lúgubres o siniestros ya contaba con una larga tradición en el cine para cuando se estrena esta película (y después la ha seguido teniendo), con apariciones en películas previas como Dr. Jekyll and Mr. Hyde (1932), The Raven (1935) o Break of Hearts (1935), entre otras. 
Un paso más en la utilización del repertorio clásico como representación de este momento de cambio sería su trivialización y satirización, como ocurre en La escalera de caracol (The Spiral Staircase, Robert Siodmak, 1946), cuya escena inicial se desarrolla en un cinematógrafo de principios del siglo XX. En él se proyecta una película que la pianista acompaña con una variación rítmica del Vals en La menor $n^{\circ} 2$. Este es ensamblado después mediante una escala descendente con una interpretación descuidada del primer movimiento de la Sonata Patética. De este modo, dos piezas de gran profundidad interpretativa quedan banalizadas por el contexto en el que se escuchan, sacadas de su pedestal mitificador. Por otro lado, el culto a la partitura y a la obra inamovible del genio romántico quedan vulgarizados por las manipulaciones que realiza la intérprete para adecuar ese repertorio a la proyección fílmica.

\section{Crisis social: música clásica ¿para todos?}

Derivada en cierto modo de esta crisis cultural, la música clásica diegética suele implicar también una crisis social, pues será aceptada o rechazada según qué colectivo de la sociedad estadounidense la escuche. Por motivos en los que no entraremos aquí, a lo largo de los años se ha ido forjando la idea popular que liga esta música con conceptos poco queridos por el gran público, como el esnobismo o la cultura elitista. Así, parece establecerse una relación entre la música clásica y algo poco deseable como el clasismo y la prepotencia. El estilo musical que aquí nos ocupa queda por tanto rechazado por los espectadores, que por el contrario desean identificarse con lo que el sociólogo Georg Luckács denominó héroe mediocre: un hombre corriente en su escenario local que ve con claridad los conflictos sociales de su época (Burke, 2003: 301). En el contexto del film noir, esta figura se encarna en el hard boiled detective con el que el público debe empatizar, y a quien raramente veremos escuchando o interpretando música clásica.

Esta asociación de las élites con el gusto por este repertorio, como práctica social ${ }^{10}$ o por afición, aparece frecuentemente el cine negro. Cuando el Dr. Elliott, el psiquiatra protagonista en A través del espejo (The Dark Mirror, Robert Siodmak, 1946), se encuentra en su casa estudiando el intrigante caso de las gemelas Ruth y Terry, escucha la $4^{a}$ Sinfonía en Mi menor (Brahms). En ese momento, recibe la visita del inspector Stevenson, quien parece desagradado por la música y le pide que apague el aparato reproductor.

10 El ambiente de ocio musical público (en contraposición al doméstico) de los colectivos elitistas queda reflejado en dos ejemplos. Por un lado en Amor que mata (Possessed, Curtis Bernhardt, 1947), donde Louise y Carol Graham acuden a un recital de piano que incluye en su programa el Carnaval de Schumann. En este caso, la pieza actuaría también como leitmotiv diegético, pues es la que tocaba su ex amante David Sutton en la intimidad, y escucharla supone para Louise un recordatorio de su relación fracasada. Por otro lado, resulta desconcertante para el espectador, pues la otrora enfermera no solía frecuentar este tipo de eventos, a los que se aficiona después de entrar en la distinguida familia Graham. El segundo ejemplo se encuentra en Luz en el alma (Christmas Holliday, Robert Siodmak, 1944), donde los protagonistas (él, heredero de una rica familia de largo linaje) se conocen durante un concierto que finaliza con la Muerte de Isolda. De nuevo la música, además de ejercer una función narrativa describiendo a un personaje y sus gustos, adquiere un cometido de metatexto, pues anticipa el trágico final de la pareja que se conoce durante su escucha. 
Stevenson: Remember me?

Elliott: Of course, Lieutenant. Come on in... Sorry!

Stevenson: I don't mind ordinary music, it's the wonderful stuff that bores me.

Elliott: That's snobbish.

La frase de Stevenson tiene enjundia. Dice que no le importa escuchar ordinary music, un calificativo que no parece casual: música corriente, común... En cambio, la música extraordinaria es la que le aburre (nótese además el desdén del inspector hacia lo que califica de maravilloso, designándolo como stuff). Así pues, el héroe mediocre, el personaje inmerso en la realidad social y criminal de su época, detesta una música a la que, sin embargo, reconoce cualidades de bondad, y prefiere la música común — popular, accesible para todos, facilitando así la identificación del público con Stevenson-. Por su parte el Dr. Elliott, un profesional liberal, menos conectado con el mundo real, absorto en sus estudios de psiquiatría ${ }^{11}$, prefiere escuchar Brahms. Merece la pena que nos detengamos un momento en la traducción que se realizó al castellano de esta frase: "No me importa la música moderna. Es la música buena la que me aburre". De lo que deducimos que primero, en España se entendió que lo que Stevenson llamaba ordinary music era música moderna, probablemente refiriéndose a la que fue la música icónica de este cine, el swing (Miklitsh, 2011: 11); y segundo, la música clásica, la que escucha Elliott, es "la buena".

La asociación de la música clásica con personajes de formación elevada o posición social privilegiada continúa en Encadenados (Notorious, Alfred Hitchcock, 1946). Alicia es la hija de un ex espía nazi, juzgado y condenado en Estados Unidos. Para su redención, es captada para espiar a los colaboradores de su padre, instalados en Río de Janeiro, seduciendo a su acaudalado cerebro Alexander Sebastian. Cuando entra por primera vez en la gran mansión del que será su marido, los cómplices de su padre se encuentran informalmente reunidos, acompañados por Carnaval. "Chopin"12. Cuando Alicia les es presentada, vemos que todos tienen unos modales exquisitos $\mathrm{y}$, dado que la música para y no vemos a ningún pianista asalariado, entendemos que quien estaba interpretando era uno de ellos. Una vez más, el repertorio clásico representa a un colectivo acaudalado y de cultura elevada, en este caso procedente de Europa y, precisamente, de la zona a la que más se asocia este estilo.

La querencia por parecerse a los grupos económicamente privilegiados, y de tener la formación necesaria para integrarse en ellos, se evidencia en Alma en suplicio (Mildred Pierce, Michael Curtiz, 1945), la historia de una familia monoparental en

11 Un caso similar es el de David Sutton, ingeniero en Amor que mata (Possessed, Curtis Bernhardt, 1947), quien toca al piano Carnaval "Chopin". Es interesante además la jerarquización que realiza en las relaciones amorosas y su equivalencia musical, pues a las mujeres con las que dice mantener relaciones serias les dedica Schumann, mientras que las relaciones menos formales se merecen a Gershwin o "something light and frivolous like Mozart".

12 Este concepto en el que un grupo reducido y selecto de personas, de alta cultura y posibilidades económicas, se reúnen privadamente como si de una secta se tratara y se acompañan de música pianística en directo, se repite en La séptima victima (The Seventh Victim, Mark Robson, 1943). Una empresaria ha desaparecido y todo parece señalar a un grupo de paladistas (sociedad satánica) que frecuentaba quienes, cuando se reúnen, son acompañados por el Vals en La b Mayor y la Sonata Claro de Luna. 
la que se contraponen el modelo de la madre, Mildred, una mujer que con esfuerzo monta su propia cadena de restaurantes; y el de su hija Veda, a la que su madre, en el deseo de que tenga un futuro más prometedor que el de ella misma, le proporciona educación musical en canto y piano, como indica en su propio relato en voice-over: "I was doing fine. I was able to afford an expensive singing teacher for Veda". De nuevo, en este caso queda patente el esnobismo atribuido al estilo de vida al que aspira Veda, representado por el repertorio que toca, el Vals en Mi bemol Mayor. La crisis generada por el choque de los estilos de vida de la mujer hecha a sí misma, y de la joven privilegiada que lo ha tenido fácil, queda representada por un repertorio aprendido en unas clases que no están al alcance de cualquier bolsillo (la propia Mildred indica que son caras). De igual modo, tal como indica Cain en su novela, la joven se empeña en avergonzar a su madre hablándole con condescendencia de la nueva pieza que está aprendiendo ${ }^{13}$, empleando "the full French pronunciation, and obviously, enjoyed the elegant effect. She spoke in the clear, affected voice that one associates with stage children", resaltando de nuevo la afectación y artificialidad de los entornos en los que predomina el repertorio clásico ${ }^{14}$ :

\author{
Mildred: How was your lesson? \\ Veda: I'm learning a new piece \\ Mildred: Are you? \\ Veda: "Valse Brillante". That means Brilliant Waltz.
}

\title{
5. Crisis personal: las sombras son más oscuras al lado de una luz radiante
}

A menudo - no solo en el cine negro- el uso del repertorio clásico en el cine resulta en dos tipos de mensajes: redundante o contrapuesto. El primer caso ocurre porque la música clásica tiene asociados valores de equilibro y orden, resultado de la formación del canon musical; es asumida como bella y, por asimilación y herencia del pensamiento platoniano, lo bello es bueno. Por lo tanto, puede ser asociada a personajes de carácter bondadoso: estaríamos hablando entonces de que esta música actuaría como signo de identidad o semejanza. Sería el caso de El beso de la muerte (Kiss of Death, 1947), en la que el protagonista Nick visita a sus hijas que están tomando su lección de piano junto con sus compañeras, una de las cuales interpreta Para Elisa. Un ejemplo similar lo constituiría Que el cielo la juzgue (Leave Her to Heaven, John M. Stahl, 1945), ya que el sosiego del repertorio que interpreta Ruth constituye un oasis acorde con su carácter pacífico, en contraposición con el

13 Veda querría emular a esas señoritas de familias adineradas (a veces de rancio abolengo, y otras de nuevos ricos) que recibían una educación musical, de adorno o con vistas profesionales, tal como ocurre en Que el cielo la juzgue (Leave her to heaven, 1945) donde Ruth, una de las hijas de la acaudalada familia Berent, ensaya y ofrece veladas musicales domésticas con el Nocurno $\mathrm{n}^{\circ} 2$ en el piano de cola del lujoso rancho familiar.

14 Esta connotación queda acentuada cuando la vida de Veda se tuerce y, ya fuera del paraguas económico materno, debe trabajar como cantante en un club nocturno donde debe interpretar repertorio popular de café cantante. 
apasionamiento descontrolado de su hermanastra Ellen (Miklitsch, 2011: 152). En ambos casos, nos encontramos ante un claro ejemplo de redundancia de significados, pues esa bondad de la música clásica es coherente con la pureza de espíritu de los personajes asociados.

Pero quizá uno de los mejores ejemplos para ilustrar el uso de esta música como signo de semejanza sea la película ¿Ángel o diablo? (Fallen Angel, Otto Preminger, 1945). El protagonista, Eric, sufre una crisis personal, pues se ve en el dilema de elegir entre dos mujeres muy distintas, cuyas representaciones musicales son contrapuestas. Por una parte, Stella, interesada y desleal; por otra June, discreta y sincera. La primera escucha Slowly ${ }^{15}$ una y otra vez en la jukebox del café donde trabaja, al tiempo que le gusta disfrutar de los placeres de la vida como beber, ir a la playa o bailar swing. Por su parte June, más austera, toca en el órgano de la iglesia obras litúrgicas de Beethoven, Brahms y Bach. Se asocia por tanto a Stella, la femme fatale, a la música popular y el placer hedonista; mientras que June, la mujer con valores de bondad, es representada con tres de las grandes " $\mathrm{B}$ " de la música clásica y, aún más allá, la elección del instrumento que ella interpreta y el contexto en el que lo toca la envuelven en un halo de espiritualidad. No hay por tanto significados equívocos y, mediante estas asociaciones, se perpetúa la idea de la vinculación de la música clásica a lo bello, bueno y equilibrado - June - , mientras que la música popular representa lo mundano y no siempre conveniente - Stella- .

Estos tres ejemplos presentes en El beso de la muerte, Que el cielo la juzgue y ¿Ángel o diablo? son claras representaciones del signo de semejanza. Sin embargo, aquí nos interesan más los casos en los que la música clásica ejerce como signo de contradicción, ya que es en estas ocasiones cuando actúa representando diversas crisis, y es de hecho cuando las interpretaciones resultan más ricas. En estas situaciones la música clásica se emplea con función de contraste para representar, por un lado, crisis relacionadas con los protagonistas - si, por ejemplo, por su propia naturaleza o la de sus actos, el personaje no representa esos valores de bondad atribuidos a la música clásica - o crisis ocasionadas por situaciones extremas - la ejecución del crimen, estados emocionales alterados- . Si, como hemos indicado, la música clásica tiene asociados valores de equilibro y orden, que aparezca durante la comisión de un crimen - la transgresión del orden establecido- ${ }^{16}$, o asociada a un personaje malvado - como ocurre con los paladistas en La séptima víctima- o que esté pasando por algún conflicto que le desequilibre, hará que el espectador reciba mensajes contradictorios. En este punto, la música clásica como signo está transmitiendo el significado contrario al que tiene de forma adquirida, y por ello la interpretación se vuelve antagónica, una especie de cuadro tenebrista en el que la oscuridad es acentuada por una luz contrastante.

16 Por ejemplo, en Al borde del peligro (Where the sidewalk ends, 1950) el protagonista mata a un hombre por accidente, y tanto el crimen como la posterior visita de su escena son enmarcados por planos de una anciana que vive en el mismo edificio, y que escucha en la radio la Pequeña Serenata Nocturna. Esta música ejerce de contraste con la situación extrema que ha tenido lugar unos pisos más arriba, oponiendo la violencia de la misma a la candidez de la pieza. 
En Carretera 301 (Highway 301, Andrew L. Stone, 1950) Mary, la esposa de un gánster, es consciente de las acciones delictivas de su marido, pero prefiere ignorarlas y disfrutar de los frutos de dichos crímenes, llegando a intervenir en los mismos. Sin embargo, su mayor entretenimiento consiste en aferrarse a su radio y escuchar a todas horas música de órgano de un estilo muy concreto ${ }^{17}$ : el desarrollado entre finales del siglo XIX y principios del XX, en el contexto de los movimientos del Cecilianismo y el Motu Proprio de 1903, que proponían reformar la música litúrgica hacia una espiritualidad más sobria. El hecho de que un personaje aparentemente carente de valores escuche de forma casi compulsiva un estilo musical con connotaciones quasi místicas puede interpretarse de diversas formas: quizá se trata de un estímulo relajante en medio de la vida criminal que, unido al consumo de alcohol, le ayuda a olvidar; o tal vez es un deseo inconsciente de redención por parte de Mary ante una posible crisis moral.

La crisis personal reflejada en Encrucijada de odios (Crossfire, Edward Dmytryk, 1947) se debe a que el protagonista Mitchell, como soldado estadounidense que ha luchado en la Segunda Guerra Mundial, sufre lo que entonces se denominaba "fatiga de combate". La presencia del Trastorno por Estrés Post Traumático provoca en él el deseo de beber ${ }^{18}$, y está muy presente en un intercambio de palabras entre el ex combatiente y otro veterano, Samuels, siendo el último el que parece más consciente del problema y el que mejor lo verbaliza:

Samuels: She says you're not drinking but you're getting drunk anyway. Anybody that can do that has got a problem. It's a funny thing, isn't it?

Mitchell: Very funny.

Samuels: It's worse at night, isn't it? I think maybe it's suddenly not having a lot of enemies to hate anymore [...]. We don't know what we're supposed to do. We don't know what's supposed to happen. We're too used to fighting. But we just don't know what to fight.

El personaje de Samuels resulta intrigante. Sabemos desde el principio que es la víctima, pero poca más información se nos da sobre él, salvo que es judío ${ }^{19}, y$ que parece un hombre afable y exquisitamente educado. La noche de su asesinato conocemos su casa, en la que él y Mitchell toman unas copas, y mientras Samuels pone un disco en un gramófono aquél lucha contra su estado de embriaguez. El hecho de que la música reproducida por el disco sea el popular vals Geschichten

17 Aunque el estilo es fácilmente reconocible, no hemos logrado identificar las piezas.

18 Un caso de crisis personal que también desemboca en la adicción al alcohol es el de Don Birnam en Días sin huella (The Lost Weekend, Billy Wilder, 1945). En su caso, el desarrollo de la enfermedad se debe a que es un escritor sin éxito que acude al teatro a ver La Traviata, y se encuentra con que su dependencia le persigue, pues en la escena se recrea el pasaje del famoso dúo Libiamo ne'lieti calici. Aquí la música hace consciente al personaje de su síndrome de abstinencia, pero sobre todo ejerce como contrapunto y representación de su crisis, ya que la alegría de lo que ocurre en el escenario no concuerda con el infierno que sufre Birnam en su adicción.

19 La película muestra un crimen de odio antisemita. Sin embargo, en la novela en la que se basa (The Brick Foxhole, Richard Brooks, 1945) el objeto de odio es homosexual (Barson, 2013), un elemento que cambiaron en la película debido al Código Hays (que lo consideraba una perversión sexual) y aprovechando la oleada de rechazo al antisemitismo tras el reciente conflicto en Europa. 
aus dem Wienerwald actúa aquí de varias maneras. Por un lado, Samuels parece un hombre que ha recibido una buena educación, versado en la disciplina musical como indica el piano de cola de su salón con partituras en proceso de estudio en el atril. $\mathrm{Su}$ gusto por los valses straussianos no nos sorprende y volveríamos al mensaje de que las personas instruidas gustan de este repertorio. Pero al mismo tiempo la pieza actúa de contrapunto a la crisis personal de Mitchell, que lucha por recuperar su identidad tras la guerra al encontrarse de pronto en esa no man's land.

El carácter desenfadado del vals en contraposición al ánimo lúgubre del soldado es sólo la lectura superficial, pues si ahondamos más en el significado veremos que es mucho más profundo (aunque desconocemos hasta qué punto intencionado). El título del vals, Cuentos de los bosques de Viena, será el mismo que el escritor alemán Ödön Josef von Horváth pondrá a una obra teatral en 1931, una tragicomedia ambientada en los suburbios de la Viena anterior a la anexión de Austria a la Alemania nazi. Una historia cómica ambientada en el lugar donde Mitchell fue combatiente — no específicamente Austría, pero sí los territorios ocupados por la Alemania Naziresalta el dolor por la alegría perdida en el mismo lugar donde el soldado desarrolla su enfermedad, y nos hacen empatizar aún más con su drama.

En Sospecha (Suspicion, Alfred Hitchcock, 1941) el repertorio clásico actúa a la vez como leitmotiv diegético y como desencadenante de la resolución de una crisis personal. Antes aludíamos a ejemplos en los que el repertorio clásico de salón era habitual en la representación de veladas de la alta sociedad. En esta línea escuchamos el vals Wiener Blut que, tras su primera aparición en un baile de sociedad, acabará adquiriendo relevancia a lo largo de la película, actuando como un motivo recurrente que representa los momentos de felicidad en la relación entre los dos protagonistas, Lina y Johnny: constituye su primer baile en público, es lo primero que escuchan al volver a casa tras la luna de miel y, cuando Lina se encuentra en plena crisis personal por la sospecha de que su marido quiere asesinarla, este vals será el elemento que resuelva su angustia, haciéndole recordar su amor por su marido y volviendo al estado de calma.

El último ejemplo viene representado por una interesante escena en Fuerza bruta (Brute Force, Jules Dassin, 1947). Tras el motín de los reclusos de una prisión, el despiadado alcaide Munsey interroga a uno de ellos, primero solo con la palabra y después torturándolo. La escena es magistralmente enmarcada a nivel estructural con la obertura de Tannhäuser, que comienza cuando lo hace el interrogatorio y, a medida que este cobra intensidad, lo hace junto con la música. Ambos paran abruptamente en una suerte de anticlímax cuando Munsey no obtiene respuestas y apaga repentinamente el tocadiscos. Esta secuencia resulta perturbadora por cuanto vemos un hombre brutal seleccionando deliberadamente una pieza wagneriana que trata sobre la redención a través del amor y la usa como motivación en un contexto de violencia casi ceremonial — tal vez, como indica Miklitsch, 2017: 135, en una especie de rito de exaltación de sí mismo como Übermensch-.

\section{6. Últimas reflexiones: el canon musical como signo del conflicto}

Los creadores de cine negro en su época de auge llevaron consigo sus fantasmas desde una atribulada Europa hasta Estados Unidos. La identidad judía de muchos de ellos jugaría a favor del desarrollo de la estética y narrativa noir, que para entonces 
ya estaba en proceso de formación. Por una parte, el hecho de que el pensamiento judío eligiera el Expresionismo como forma de arte cristalizaría en el uso de una serie de recursos formales que intensificaban la angustia como emoción principal. Por otro lado, la temática del cine negro encontró un matrimonio conveniente en la consciencia del conflicto y el gusto por el realismo que trajeron unos directores que no solo eran emigrantes, sino exiliados; que no fueron invitados, sino que llegaron porque huían para salvar su vida (Brook, 2009: 2-3). Así las cosas, se formó la tormenta perfecta y, como resultado, un cine riquísimo en la representación de múltiples tipos de crisis.

Observando la muestra de dieciocho películas escogidas de entre cincuenta pertenecientes a la era dorada del film noir en Hollywood podemos establecer que, a pesar de que la música incidental es un fantástico vehículo del dramatismo inherente a este género, la música diegética resulta interesante como elemento de representación realista de la crisis. Y si bien el jazz (concretamente el swing) es el estilo musical diegético más querido, hemos encontrado múltiples ejemplos en los que la música clásica juega un papel crucial.

Sin entrar en la polémica que pueda implicar delimitar lo que es música clásica - o la pertinencia del término-, los propios diálogos de las películas califican como tal un repertorio que responde a los clichés que habitualmente la definen. Sin embargo, el espectro de obras seleccionadas para estas películas es más reducido de lo que cabría esperar, pues en su mayoría está constituido por obras instrumentales de compositores de origen germano de la segunda mitad del siglo XIX. Esto no hace sino reafirmar y perpetuar el canon musical interpretativo y pedagógico formado a partir de las preferencias de críticos y connoisseurs burgueses que han patrocinado la actividad musical, desde que las instituciones eclesiásticas y monárquicas dejaran de ser sus principales mecenas (Webber, 1999: 353).

No creemos que sea casualidad que las películas que reafirman un canon germanodecimonónico en la música diegética hayan contado con directores y compositores de bandas sonoras con un origen muy concreto. Su procedencia centroeuropea y ascendencia judía es mayoritaria, aunque más entre los directores que en los compositores: Preminger, Curtiz, Sekely, Wilder, Steiner, Salter o Rózsa, del antiguo Imperio Austrohúngaro; Siodmak, Bernhardt y Waxman, del antiguo Imperio Alemán; Dassin, Dmytryck o Newman, estadounidenses de segunda generación con padres procedentes estas dos áreas. Otros orígenes, como el británico — Hitchcock y Mockrydge - , el antiguo Imperio Ruso — Stahl y Tiomkin — o estadounidense - Hathaway, Raksin, Lava, Kaplan y Webb-, forman un grupo mucho menos homogéneo que el anterior.

No resulta extraño entonces que, tanto si el repertorio diegético fue seleccionado por los directores como si lo fue por los compositores, acabara siendo integrado por un conjunto de obras de carácter tan homogéneo como la propia procedencia geocultural de estos creadores, siendo que los directores estarían acostumbrados a él como canon interpretativo, y los compositores lo considerarían canon escolástico ${ }^{20}$. La afinidad estilística de estas obras diegéticas con el lenguaje musical que habían estudiado estos compositores, y que plasmaban en su música extradiegética,

20 Uno de los mayores exponentes de este estilo sería Max Steiner, entre cuyas referencias podemos citar a Beethoven, Strauss o Mahler, oscilando su estilo entre el dramatismo operístico wagneriano y el impresionismo francés, pasando por la tradición europea del cabaret (Slobin, 2008: 6). 
encuentra su máxima expresión en la integración y cita (literal o manipulada) de temas reconocibles en su música incidental, como ocurre en Amor que mata (Carnaval. "Chopin"), La sombra de una duda (Vals de la Viuda Alegre, Franz Léhar), La fuerza del destino (Cuarteto op. 131, Beethoven) o Christmas Holliday (Muerte de Isolda).

En la selección de las musicalizaciones de estas crisis mediante el repertorio canónico conviven motivos que tienen que ver con la afinidad estilística de los compositores y los gustos personales adquiridos por los directores en Europa, que a veces chocaban con la consideración de esta misma música en un país cuya identidad cultural se iba alejando cada vez más de la europea. Como resultado, la música clásica se utiliza en la representación de una crisis cultural, con repercusiones sociales. Por otra parte, los valores estéticos de la música clásica de bondad, equilibrio y belleza adquiridos por su consideración como canon escolástico, sirven para representar crisis personales con matices muy ricos.

Así, un repertorio clásico que podríamos definir mayoritariamente como germano, tardodecimonónico e instrumenta ${ }^{21}$ se ha utilizado en el audiovisual con múltiples funciones. En primer lugar, expresivas, por ejemplo, para subrayar el carácter tormentoso de una relación en Amor que mata, o el estado emocional de un personaje - la Muerte de Isolda amplifica la tristeza de Abigail en Luz en el alma - . En segundo lugar, cumple funciones estructurales, aportando ritmo a la narrativa y puntuando su discurso, como hace la Obertura de Tannhäuser en Fuerza bruta. Pero sin duda, la función para la que ha resultado ser más eficaz —o por lo menos ha tenido un uso más frecuente - ha sido la narrativa: como metatexto - el vals Geschichten aus dem Wienerwald en Encrucijada de odios-; intensificando los significados de la narración, ya sea de forma coherente o contradictoria respectivamente, la oposición música popular / clásica en ¿Ángel o diablo?, o su identificación con un grupo satánico en La séptima víctima -; como elipsis narrativa - el Carnaval de Schumann como leitmotiv de la relación entre Louise y David en Amor que mata - ; y por último, pero no menos importante, la descripción de un personaje o grupo social (normalmente personas cuyo elitismo viene determinado bien por su alta formación y cultura, o bien por su poder adquisitivo ${ }^{22}$.

Nos quedan por plantear algunas preguntas partiendo de estas breves reflexiones. Si la música clásica, sin tener una presencia mayoritaria, ha resultado ser tan eficaz en la representación de la crisis en el cine negro ¿qué podemos esperar de la música popular? Si es utilizada como leitmotiv por los compositores en su música incidental ¿cómo han integrado temas clásicos reconocibles en sus partituras? Si tiene valores platonianos de bondad y belleza, ¿cómo ha terminado convirtiéndose en signo de contradicción, representando la maldad? Dejaremos las respuestas a estas cuestiones para un futuro próximo.

21 Seguramente es más adecuada la música instrumental que la vocal como vehículo para el mensaje del film noir, al estar libre la primera del condicionante de la palabra y ser más susceptible de funcionar como música programática.

22 Con algunas excepciones, en las que se asocian piezas que han llegado a ser "clásicos populares" a personajes humildes y que las interpretan casi como canciones de trabajo, como la propietaria italiana del restaurante en La séptima víctima, que canta Caro mio ben (Giordani) mientras cocina; o el mecánico de garaje en La cicatriz (Hollow Triumph, Steve Sekely, 1948), que silba El Danubio Azul mientras limpia. 


\section{Anexo}

\begin{tabular}{|c|c|c|c|}
\hline PELÍCULA & $\begin{array}{l}\text { COMPOSITOR } \\
\text { BANDA SONORA }\end{array}$ & $\begin{array}{l}\text { BLOQUE } \\
\text { MUSICAL }^{23}\end{array}$ & MÚSICA DIEGÉTICA \\
\hline \multirow[t]{3}{*}{ Suspicion } & \multirow[t]{3}{*}{ Franz Waxman } & $00: 18: 11$ & \multirow[t]{3}{*}{ Wiener Blut (J. Strauss II, 1873). } \\
\hline & & $00: 28: 24$ & \\
\hline & & 01:06:18 & \\
\hline \multirow[t]{3}{*}{$\begin{array}{l}\text { The Seventh } \\
\text { Victim }\end{array}$} & \multirow[t]{3}{*}{ Roy Webb } & $00: 33: 58$ & $\begin{array}{l}\text { Vals en La b Mayor, } N^{o} .15(\mathrm{~J} . \\
\text { Brahms , 1865) }\end{array}$ \\
\hline & & $00: 36: 36$ & $\begin{array}{l}\text { Sonata para piano en Do \# } \\
\text { menor, "Claro de Luna". Adagio } \\
\text { sostenuto (L. van Beethoven, } \\
\text { 1802) }\end{array}$ \\
\hline & & $00: 41: 14$ & Caro mio ben (G. Giordani, 1785). \\
\hline $\begin{array}{l}\text { Christmas } \\
\text { Holliday }\end{array}$ & Hans J. Salter & $00: 44: 22$ & $\begin{array}{l}\text { Tristán e Isolda. "Muerte de } \\
\text { Isolda" (R. Wagner, 1859). }\end{array}$ \\
\hline $\begin{array}{l}\text { Mildred } \\
\text { Pierce }\end{array}$ & Max Steiner & $00: 25: 07$ & $\begin{array}{l}\text { Vals en Mi b mayor / Grand Valse } \\
\text { Brillante (F. Chopin, 1833) }\end{array}$ \\
\hline Fallen Angel & David Raksin & $00: 31: 55$ & $\begin{array}{l}\text { Música de órgano improvisada. } \\
\text { Se alude en un cartel (algunas } \\
\text { obras inexistentes): } \\
\text { - Stabat Mater (L. van Beetho- } \\
\text { ven). } \\
\text { - Requiem (J. Brahms). } \\
\text { - Jesus in Gethsemane (J. S. } \\
\text { Bach). }\end{array}$ \\
\hline $\begin{array}{l}\text { The Spiral } \\
\text { Staircase }\end{array}$ & Roy Webb & $00: 01: 25$ & $\begin{array}{l}\text { Vals en La menor } n^{\circ} 2 \text { (F. Chopin, } \\
1835) . \\
\text { Sonata } n^{\circ} 8 \text { en do menor, } \\
\text { "Pathétique". Grave. (L. van } \\
\text { Beethoven, 1798). }\end{array}$ \\
\hline \multirow[t]{2}{*}{$\begin{array}{l}\text { Leave her to } \\
\text { heaven }\end{array}$} & \multirow[t]{2}{*}{ Alfred Newman } & $00: 12: 11$ & $\begin{array}{l}\text { Nocturne } N^{o} .2 \text {, op. } 27 \text { (F. Chopin, } \\
\text { 1836). }\end{array}$ \\
\hline & & $00: 16: 55$ & $\begin{array}{l}\text { Ballade } n^{\circ} 1 \text {, op. } 23 \text { (F. Chopin, } \\
\text { 1835) }\end{array}$ \\
\hline
\end{tabular}

23 El minutaje y las obras musicales se refieren a las películas en versión original, datos que no siempre coinciden con las versiones dobladas al castellano. 


\begin{tabular}{|c|c|c|c|}
\hline $\begin{array}{l}\text { The Lost } \\
\text { Weekend }\end{array}$ & Miklós Rozsa & $00: 28: 41$ & $\begin{array}{l}\text { La Traviata "Libiamo ne'lieti } \\
\text { calici" (G. Verdi, 1853) }\end{array}$ \\
\hline $\begin{array}{l}\text { The Dark } \\
\text { Mirror }\end{array}$ & Dimitri Tiomkin & $00: 23: 20$ & $\begin{array}{l}\text { Sinfonía } n^{\circ} 4 \text { en Mi menor. Allegro } \\
\text { non troppo }(\mathrm{J} . \text { Brahms, } 1885) \text {. }\end{array}$ \\
\hline Notorious & Roy Webb & $00: 40: 25$ & $\begin{array}{l}\text { Carnaval. "Chopin" (R. } \\
\text { Schumann, 1835) }\end{array}$ \\
\hline Kiss of Death & David Buttolph & $00: 36: 15$ & $\begin{array}{l}\text { Bagatella } \mathrm{n}^{\mathrm{o}} 25 \text { en La menor } \\
\text { "Para Elisa" (L. van Beethoven, } \\
\text { 1810) }\end{array}$ \\
\hline Brute Force & Miklós Rozsa & $01: 16: 25$ & $\begin{array}{l}\text { Tannhauser "Obertura" }(\mathrm{R} . \\
\text { Wagner, 1845). }\end{array}$ \\
\hline Crossfire & Roy Webb & 00:27:03 & $\begin{array}{l}\text { Geschichten aus dem Wienerwald. } \\
\text { (J. Strauss II, 1868). }\end{array}$ \\
\hline \multirow[t]{3}{*}{ Possessed } & \multirow[t]{3}{*}{ Franz Waxman } & $00: 13: 53$ & $\begin{array}{l}\text { Carnaval. "Chopin" (R. } \\
\text { Schumann, 1835) }\end{array}$ \\
\hline & & $00: 55: 24$ & $\begin{array}{l}\text { Vals del Emperador. (J. } \\
\text { Strauss, 1888). }\end{array}$ \\
\hline & & 01:00:46 & $\begin{array}{l}\text { Carnaval. "Preludio" y "Chopin" } \\
\text { (R. Schumann, 1835) }\end{array}$ \\
\hline $\begin{array}{l}\text { Hollow } \\
\text { Triumph }\end{array}$ & Sol Kaplan & $00: 46: 31$ & $\begin{array}{l}\text { El Danubio Azul (J. Strauss, } \\
\text { 1866). }\end{array}$ \\
\hline \multirow[t]{2}{*}{$\begin{array}{l}\text { Where the } \\
\text { Sidewalk } \\
\text { Ends }\end{array}$} & \multirow[t]{2}{*}{ Cyril Mockridge } & $00: 18: 38$ & $\begin{array}{l}\text { Serenata } n^{\circ} 13 \text { para cuerdas en } \\
\text { Sol Mayor "Pequeña Serenata } \\
\text { Nocturna" (W. A. Mozart, 1787). }\end{array}$ \\
\hline & & 00:19:44 & Vals no identificado \\
\hline \multirow[t]{4}{*}{ Highway 301} & \multirow[t]{4}{*}{ William Lava } & $00: 24: 35$ & \multirow{4}{*}{$\begin{array}{l}\text { Música de órgano en la radio. } \\
\text { Obras no identificadas. }\end{array}$} \\
\hline & & $00: 37: 30$ & \\
\hline & & 00:48:57 & \\
\hline & & 01:05:55 & \\
\hline \multirow[t]{2}{*}{$\begin{array}{l}\text { Sunset } \\
\text { Boulevard }\end{array}$} & \multirow[t]{2}{*}{ Franz Waxman } & $00: 26: 15$ & $\begin{array}{l}\text { Toccata y Fuga en Re menor (J. S. } \\
\text { Bach, ca. 1705). }\end{array}$ \\
\hline & & 00:58:44 & Sobre las Olas (J. Rosas, 1887) \\
\hline
\end{tabular}

\section{Bibliografía}

The American Film Institute Catalog of Motion Pictures Produced in the United States: Feature Films, 1931-1940.

Barson, M. (2013). "Richard Brooks". Enciclopaedia Britannica. Recuperado de: https://www.britannica.com/biography/Richard-Brooks\#ref1182325. (Fecha de acceso: 22/12/2012) 
Borde, R.; Chaumeton, E. (2002). A panorama of American Film Noir (1941-1953). San Francisco: City Light Books.

Brook, V. (2009). Driven to Darkness: Jewish Emigré Directors and the Rise of Film Noir. New Jersey: Rutgers University Press.

Brown, R. S. (1994). Overtones and Undertones: Reading Film Music. University of California Press.

Burke, P. (2003). Formas de hacer historia. Traducción: José Luis Gil Aristu y Francisco Martín Arribas. Madrid: Alianza Editorial.

Butler, D. (2002). Jazz Noir: Listening to Music from Phantom Lady to The Last

Seduction. Westport: Praeger Publishers.

Cain, J. M. (1989 [1941]). Mildred Pierce. Nueva York: Vintage Book Edition.

Coma, J. (1990). Diccionario del Cine Negro. Barcelona: Plaza Janés Editores.

Degler, C. N. (1986). Historia de Estados Unidos. El desarrollo de una nación, 1860-1985. Barcelona: Editorial Ariel, S. A.

Martín, A. (2007). "El género policíaco: esencia y personajes" en Álex Sánchez Zapatero y Javier Martín Escribá (Eds.), Informe confidencial. La figura del detective en el género negro, Valladolid: Difácil, pp. 21-34.

Miklitsch, R. (2011). Siren City: Sound and Source Music in Classic American Noir. New Jersey: Rutgers University Press. Versión Ebook.

Pavés, G. M. (2003). El cine negro de la RKO. En el corazón de las tinieblas. Madrid: T\&B Editores.

Place, J.; Peterson, L. (1996). "Some visual motifs of film noir". Alain Silver y James Ursini (Eds.) Film noir reader. New York: Lime light Editions, 65-76.

Porfirio, R.; Silver, A.; Ursini, J.. (2004). El cine negro americano. Los secretos de los cineastas del período clásico. Barcelona: Laertes.

Rodríguez de Austria Sánchez de Aragón, A. M. (2015). "El código de producción de Hollywood (1930- 1966): censura, marcos (frames) y hegemonía” en Zer, 20-39, pp. 177-193. Recuperado de: http://www.ehu.eus/zer/hemeroteca/pdfs/zer39-10-rodriguez. pdf (Fecha de acceso: 22/12/2012)

Sánchez Noriega, J. L. (1998). Obras maestras del cine negro. Bilbao: Ediciones Mensajero. Santamarina, A. (1999). El cine negro en 100 películas. Madrid: Alianza Editorial.

Silver, A., Ursini, J. (2004). Cine negro. Madrid: Taschen.

Simsolo, N. (2007). El cine negro. Pesadillas verdaderas y falsas. Madrid: Alianza Editorial.

Slobin, M. (2008). Global Soundtracks: Worlds of Film Music. Middletown, CT: Wesleyan University Press.

Wagner, J.B. (2017). Jazz and Cocktails: Rethinking Race and the Sound of Film Noir. Austin: University of Texas Press.

Webber, William. (1999) “The History of Musical Canon”. En N. Cook y M. Everest (Eds.) Rethingking Music. Oxford: Oxford University Press. 